\title{
Article \\ Plebeian Sage (Salvia plebeia R. Br) Extract Ameliorates Inflammation and Cartilage Degradation in Surgically Induced Osteoarthritis Rats
}

\author{
Eun-Byeol Lee ${ }^{1,+}{ }^{\mathbb{D}}$, Ji-Hye Choi ${ }^{1,+}{ }^{\mathbb{D}}$, Sae-Kwang Ku ${ }^{2} \mathbb{D}$, Beom-Rak Choi ${ }^{3}$, Hwan-Hee Jang ${ }^{1} \mathbb{D}^{\text {, }}$ \\ Heon-Woong Kim ${ }^{1}$, Jeong-Sang Lee ${ }^{4}$ and Sung-Hyen Lee ${ }^{1, *}$
}

1 National Institute of Agricultural Sciences, Rural Development Administration, Wanju 55365, Jeonbuk, Korea; dmsqufd11029@naver.com (E.-B.L.); jyyye@naver.com (J.-H.C.); rapture19@korea.kr (H.-H.J.); ksharrier@korea.kr (H.-W.K.)

2 College of Korean Medicine, Daegu Haany University, Daegu 38610, Kyungbuk, Korea; gucci200@hanmail.net

3 Nutracore Co., Ltd., Yeongtong, Suwon 16229, Gyeonggi, Korea; brchoi@nutracore.co.kr

4 Department of Functional Foods and Biotechnology, Jeonju University, Jeonju 55069, Jeonbuk, Korea; jslee11@jj.ac.kr

* Correspondence: 1shin@korea.kr; Tel.: +82-63-238-3681; Fax: +82-63-238-3843

+ The authors equally contributed to this work.

\section{check for} updates

Citation: Lee, E.-B.; Choi, J.-H.; Ku, S.-K.; Choi, B.-R.; Jang, H.-H.; Kim, H.-W.; Lee, J.-S.; Lee, S.-H. Plebeian Sage (Salvia plebeia R. Br) Extract Ameliorates Inflammation and Cartilage Degradation in Surgically Induced Osteoarthritis Rats. Appl. Sci. 2022, 12, 2030. https://doi.org/ 10.3390/app12042030

Academic Editor:

Alessandra Durazzo

Received: 3 November 2021 Accepted: 10 February 2022 Published: 16 February 2022

Publisher's Note: MDPI stays neutral with regard to jurisdictional claims in published maps and institutional affiliations.

Copyright: (C) 2022 by the authors. Licensee MDPI, Basel, Switzerland. This article is an open access article distributed under the terms and conditions of the Creative Commons Attribution (CC BY) license (https:// creativecommons.org/licenses/by/ $4.0 /)$.

\begin{abstract}
Osteoarthritis (OA), the most prevalent articular disease with the clinical syndrome of joint pain accompanied by varying degrees of functional limitation, reduces the quality of elderly life. In this study, the effects of Plebeian sage extract (PS) on anti-inflammatory and anti-articular cartilage degradation activities were evaluated in rats with surgically induced OA. PS supplement for 12 weeks significantly decreased Mankin scores, including inflammatory cell numbers, and improved surface cartilage damage and mean femur and tibia articular cartilage (AC) thicknesses in OA rats. PS diminished IL-1 $\beta$, IL-6, TNF- $\alpha$, MMP-2, MMP-3, and MMP-9, as well as lipocalin-2 levels in serum or cartilage, which were increased due to OA. The results suggested that PS decreased joint inflammation and loss of articular cartilage by suppressing provocative responses and synovial tissue decimation in the OA model. Thus, PS may be used as a novel potential therapeutic regime for OA in the elderly.
\end{abstract}

Keywords: Saliva plebeian; osteoarthritis; articular cartilage; inflammation; cytokine; MMPs

\section{Introduction}

Osteoarthritis (OA) is the most prevalent articular disease in the elderly [1]. The process is characterized by changes in the structure and function of the articulation, mainly due to a degenerative process that takes place in the articular cartilage [2,3]. OA is the most common clinical syndrome of joint pain accompanied by varying degrees of functional limitation that reduces the quality of elderly life [4]. Subchondral bone remodeling and a meniscal damage occur in OA, which is a whole joint disorder, affecting all joint tissues that communicate at the cellular level by releasing and responding to inflammatory mediators. Inflammation and fibrosis present in synovial membrane and in the infrapatellar fat pad (IFP) [5,6]. Synovial inflammation acts as a trigger for several symptoms of OA via the release of soluble factors that, while increasing and perpetuating cartilage damage, are used as biomarkers $[7,8]$. Inflammation may act as a contributing factor in perpetuating cartilage degradation by promoting destruction and impairing the ability of repair [9].

IL-1 $\beta$ and TNF- $\alpha$ induce other proinflammatory cytokines, such as IL-6, IL-17, and IL-18, and chemokines. Many of these factors synergize with one or another in promoting chondrocyte catabolic responses. The activation of stress- and inflammation-induced signaling, transcriptional, and posttranscriptional events may cause phenotypic shift, apoptosis, and aberrant expression of inflammation-related genes, including catabolic genes [3]. 
Nuclear factor kappaB (NF-kB) proteins constitute a family of transcription factors that are stimulated by pro-inflammatory cytokines, chemokines, stress-related factors, and extracellular matrix (ECM) degradation products. The activated NF-kB molecules trigger the expression of an array of genes, which induce destruction of the articular joint, leading to OA onset and progression [10]. These include nitric oxide synthase (NOS)-2, cyclooxygenase (COX)-2, and several matrix metalloproteinases (MMPs) [9,10]. Lipocalin-2 induced by pro-inflammatory factors in joint tissues forms covalent complexes with MMP-9 [11], and its circulating levels are elevated in aged individuals [12,13]. Increased levels of Lipocalin-2 have been found in OA SF and OA cartilage [14,15]. It has been reported that Lipocalin-2 contributes to the OA pathologies and other OA risk factors [16].

Loss of articular cartilage components, mainly ECM, which leads to tissue destruction and hypocellularity, and eventually results in loss of joint function, was found in the OA patients $[9,10,17]$. There is no cure for OA and no effective treatment to stop its progression. Current pharmacologic treatments, such as analgesics and non-steroidal anti-inflammatory drugs, may improve the pain and offer some relief, but they do not affect the progression of the disease. Further, the chronic intake of these drugs may result in severe adverse events [18]. Glucosamine and chondroitin sulfate have been shown to delay OA knee progression in several clinical trials $[19,20]$. The effectiveness of some products that are considered nutraceuticals has been widely reviewed in the literature [21,22]. The results present that nutrients, vitamins, antioxidants, and other natural components in the normal diet can affect the progression of the disease [23,24]. Many in vitro studies indicate the efficacy of specific nutrients in cartilage metabolism and their involvement in OA [25-27]. Dipsacus asperoides and Mollugo pentaphylla L. (Molluginaceae) extracts showed potent anti-inflammatory activities and protected cartilage in an OA rat model $[28,29]$. However, in vivo or rigorous clinical studies that evaluate the efficacy of these compounds in OA models are still missing. The influence of nutrients and diets on the metabolism of cartilage and OA could represent a long-term coadjuvant alternative in the management of OA. The studies show that the diets might be potential candidates for therapeutic OA treatment. Thus, our focus is to find safe and effective nutraceuticals that can control inflammation, cartilage metabolism, and OA progression.

Plebeian sage (Salvia plebeia R. Br) is an annual or biennial plant that grows in Korea, China, and India. It is used as a traditional medicine to treat inflammatory diseases, including asthma, hepatitis, and hemorrhoids [30]. Pharmacological investigations have revealed that leaf extract of Plebeian sage (PS) has anti-oxidative [30,31], anti-inflammatory [30,32], anti-asthma [32], and anti-arthritis effects [33]. The active components of Plebeian sage comprise flavonoids [34] and phenolic acid [35], which are known for their antioxidant and anti-inflammatory effects. The homoplantaginin, which is the main flavonoid from Plebeian sage, is known to have inhibitory effects on inflammation by controlling nitric oxide generation [36]. In the previous study, Plebeian sage extracted with 95\% $v / v \mathrm{EtOH}$ at $70{ }^{\circ} \mathrm{C}$ inhibited inflammatory response in a mice model of arthritis [33]. However, 50\% $v / v \mathrm{EtOH}$ or less concentration of $\mathrm{EtOH}$ and $50{ }^{\circ} \mathrm{C}$ or lower temperature are preferred as an extracting condition for the clinical trial. Health food producers prefer the condition because of its lower producing price and higher safety compared to the other condition. Thus, we have extracted Plebeian sage with 50\% $v / v$ EtOH at room temperature and have evaluated its effect in the osteoarthritis model. It is hypothesized that appropriate treatment of PS inhibits surgically induced OA due to its anti-inflammatory and articular cartilage (AC) preserving effects. The objective of this study is to verify the anti-osteoarthritis effects of PS in rats with surgically induced OA. 


\section{Materials and Methods}

\subsection{Plant Material and Its Flavonoids Contents}

\subsubsection{Sample Preparation}

Plebeian sage leaves were obtained from the natural population in a farm in the Paju area of the Gyeonggi-do (South Korea) and were authenticated by the National Institute of Agricultural Sciences. After a multiple-step cleaning process and drying, $300 \mathrm{~g}$ of Plebeian sage leaves were extracted twice with 10 times volume of $50 \% v / v$ ethanol and distilled water at room temperature for $24 \mathrm{~h}$. The extracts of PS were filtered through No. 6 filter paper (Advantec Co., Tokyo, Japan) and were concentrated by sequential use of a rotary evaporator (EYELA N-1000, Riakikai Co., Ltd., Tokyo, Japan) at $30^{\circ} \mathrm{C}$. Then, they were frozen and lyophilized (PVTFD 10R, Ilsin Lab, Yangju, Korea). The final lyophilized extract (11\% yield) was stored at -70 until required for experimental use.

\subsubsection{Analyzing Flavonoids Contents in Plebeian Sage and Its Extract}

Flavone and flavanone amounts of Plebeian sage leaf and its extract (PS) were measured as major flavonoids compounds. Reference standards of nepetin 7-O-glucoside (nepitrin), hispidulin 7-O-glucoside (homoplantaninin) and hispidulin were purchased from Sigma-Aldrich Co. (St. Louis, MO, USA). Luteolin 7-O-glucoside (cynaroside) and 6-methoxyluteolin (internal standard) were obtained from Extrasynthese (Genay Cedex, France). In addition, methanol, acetonitrile and water (Optima ${ }^{\circledR}$ LC/MS grade) were supplied from Fisher Scientific (Pittsburgh, PA, USA) and formic acid from Junsei Chemical (Tokyo, Japan). By UPLC-DAD-QToF/MS analysis, the flavone and flavanone derivatives of common sage were identified and quantified using an UPLC system equipped with a diode array detector (DAD) (ACQUITY UPLC ${ }^{\mathrm{TM}}$ system, Waters Co., Milford, MA, USA) and a QToF/MS (Xevo G2-S QToF, Waters MS Technologies, Manchester, UK). In addition, both main column (CORTECS UPLC T3 C18, $2.1 \times 150 \mathrm{~mm}, 1.6 \mu \mathrm{m}$, Waters Co.) and pre-column (CORTECS UPLC T3 VanGuard ${ }^{\mathrm{TM}}, 2.1 \times 50 \mathrm{~mm}, 1.6 \mu \mathrm{m}$, Waters Co.) were used to separate flavonoid derivatives. The analysis was conducted at a flow rate of $0.3 \mathrm{~mL} / \mathrm{min}$ and detection wavelength of $210-400 \mathrm{~nm}$ (representative wavelengths of 350 and $280 \mathrm{~nm}$ for flavone and flavanone derivatives, respectively). According to mobile phase A ( $0.5 \%$ formic acid in water) and B ( $0.5 \%$ formic acid in acetonitrile), the elution gradient profiles (total $40 \mathrm{~min}$ ) were detailed as 25\% B (20 min), 50\% B (25 min), 90\% B (30 min), 90\% B (32 min), 5\% B (34 min) and 5\% B (40 min). Mass spectra were simultaneously scanned in the range of $200-1200 \mathrm{~m} / z$ in positive ionization mode using an electrospray ionization (+ESI) source, and the parameters used were: capillary voltage $3.5 \mathrm{kV}$, sampling cone voltage $40 \mathrm{~V}$, source temperature $120^{\circ} \mathrm{C}$, desolvation temperature $500{ }^{\circ} \mathrm{C}$, and desolvation $\mathrm{N}_{2}$ gas flow $1050 \mathrm{~L} / \mathrm{h}$.

\subsection{Animal Experiments}

\subsubsection{Surgically Induced Osteoarthritis Rat Model}

OA rats, surgically induced by anterior cruciate ligament transected and partial medial meniscectomy, have been generally used to observe the anti-OA effects of various candidates [22,37]. Forty SPF male Sprague-Dawley (SD) rats (9 weeks old, body weight (BW) $321 \pm 36 \mathrm{~g}$ ) composed of normal and OA model were purchased from the Orient Bio (Sungnam, Korea). Except for the 8 rats as the sham control group (CON), the other 32 rats were used as the OA model. The OA rats confirmed as OA model with data sheets showing increased knee thickness following surgical operation compared to the Sham rats were purchased from the company. Target was left knee joint, including femur and tibia articular cartilages and synovial membranes (SM). Surgery to induce OA was performed in 32 rats $[22,37,38]$. The normal control group of rats underwent a sham operation in which a similar incision in the joint capsule have been made but anterior cruciate ligament transection and partial medial meniscectomy had not been performed. 


\subsubsection{Animals Husbandry and Experiment Protocols}

After 1 week of an adaptation period following purchase from the company, 10-week-old Sham and OA rats were randomly divided into $\mathrm{CON}$ and 4 OA groups $(\mathrm{n}=8 /$ group), respectively. Two animals per polycarbonate cage were housed at $22 \pm 2{ }^{\circ} \mathrm{C}$ and $50-55 \%$ humidity in a facility under a $12 \mathrm{~h}$ light-dark cycle with free access to a standard pellet diet and water. Experimental doses and duration for this animal study were considered from previous experiments [22,28-30]. The PS was dissolved in distilled water (DW) and fed to rats by $1 \mathrm{~mL}$ at 100 (PS1) or $300 \mathrm{mg} / \mathrm{kg}$ BW (PS2) every day for 12 weeks. An equal volume of DW used for the melting sample was treated for the sham normal control (CON), negative control (NC), and positive control (PC). PC group was subcutaneously injected with $500 \mu \mathrm{L}$ of diclofenac sodium salt $\left(\mathrm{C}_{14} \mathrm{H}_{10} \mathrm{Cl}_{2} \mathrm{NNaO}_{2}\right.$, Sigma) at $2 \mathrm{mg} / \mathrm{kg} \mathrm{BW}$ in sterilized saline into the dorsal skin with a $26 \mathrm{G}$ needle [22]. After 12 weeks of treatments, the rats were anesthetized using $\mathrm{CO}_{2}$ gas. All experimental protocols and procedures were approved by the Small Animal Care and Use Committee of the National Institute of Agricultural Sciences (NAS-201804). Body weight and diet intake were measured every week. Experimental design to evaluate in vivo anti-osteoarthritis effect of PS is shown in Figure 1.

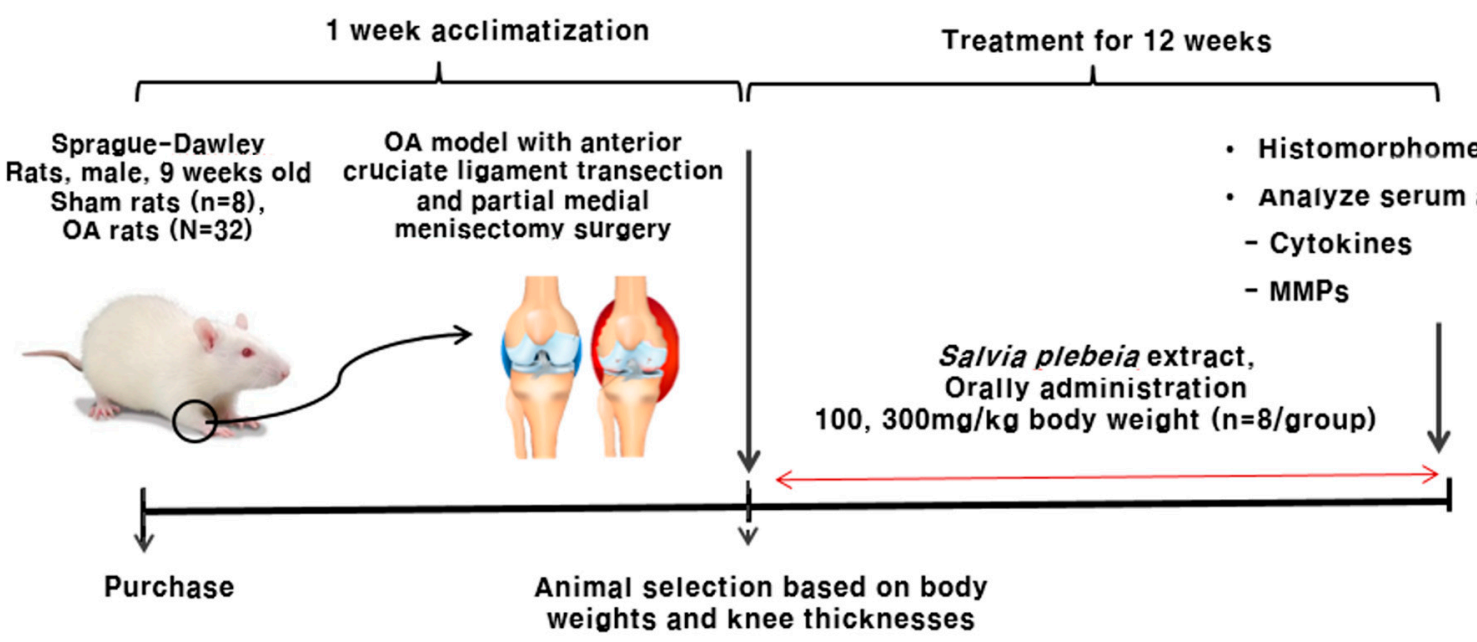

Figure 1. Experimental design for the animal study.

- Group 1: CON (normal control, sham, distilled water (DW)) $(\mathrm{n}=8)$;

- Group 2: NC (negative control, osteoarthritis (OA), DW) $(\mathrm{n}=8)$;

- Group 3: PC (positive control, OA, DW, diclofenac sodium salt $2 \mathrm{mg} / \mathrm{kg} \mathrm{BW})(\mathrm{n}=8)$;

- Group 4: PS1 (OA, low dose of PS $100 \mathrm{mg} / \mathrm{kg} \mathrm{BW})(\mathrm{n}=8)$;

- Group 5: PS2 (OA, high dose of PS $300 \mathrm{mg} / \mathrm{kg} \mathrm{BW})(\mathrm{n}=8)$.

\subsubsection{Histological Process}

One part in each knee joint, longitudinal section; one synovial cavity, including femur and tibia AC, and SM/IFP histological field in each sectioned knee joint were used (4 or 5 samples/group). All individual knee joint samples were decalcified in decalcifying solution ( $24.4 \%$ formic acid and $0.5 \mathrm{~N}$ sodium hydroxide) for 5 days. The mixed decalcifying solution was changed once per day. Each knee joint was longitudinally trimmed on part in each knee joint, including both femur and tibia $\mathrm{AC}$ with $\mathrm{SM}$, and then embedded in paraffin using an automated tissue processor (Shandon Citadel 2000, Thermo Scientific, Waltham, MA, USA) and embedding center (Shandon Histostar), and 3-4 $\mu \mathrm{m}$ thick serial two section blocks were prepared using an automated microtome (RM2255, Leica Biosystems, Nussloch, Germany) in each paraffin block. Representative sections were stained with H\&E for general histopathology and Safranin $\mathrm{O}(\mathrm{SO})$ for $\mathrm{AC}$ chondrocytes according to established methods $[37,38]$. Histological sections were prepared for all samples, and the histological 
profiles were interpreted under a light microscope (Model Eclipse 80i, Nikon, Tokyo, Japan) as blinds to group distribution during this analysis.

\subsubsection{Histomorphometrical Analysis}

The entire histological evaluation was performed by the same pathologist. Mean femur and tibia AC and SM epithelial thicknesses $(\mu \mathrm{m})$ were measured as histomorphometrical analyses on prepared longitudinally trimmed samples, using a computer-based automated image analyzer (iSolution FL ver 9.1, IMTi-solution Inc., Vancouver, British Columbia, Canada), with mean numbers of inflammatory cells infiltrated on the SM (cells $/ \mathrm{mm}^{2}$ ) according to previously established methods [22,37]. The histological fields observed in this inspection were selected around the central region of synovial cavity on the knee joint histological specimen. More than five histological fields in each knee joint section were considered to calculate each mean histomorphometrical value. To observe more detailed histopathological changes, the femur and tibia AC injuries found in the knees were evaluated and recorded using the Mankin scoring systems (Table 1) using Safranin O stain. In this system, the higher the score, the higher the level of OA (Semiquantitative scores; $\operatorname{Max}=12)$.

Table 1. Variable scores of the Mankin scoring systems.

\begin{tabular}{|c|c|c|c|}
\hline Surface Condition & Hypocellularity & Clone Formations & Stain Intensity for Safranin $\mathrm{O}$ \\
\hline $0=$ normal & $0=$ normal & $0=$ normal & $0=$ normal \\
\hline $1=$ irregular & $1=$ small decrease & 1 = occasional duos & $1=$ small decrease \\
\hline 2 = fibrillation & in color & $2=$ duos or trios & in color \\
\hline vacuoles & $2=$ large decrease in color & $3=$ multiple & $2=$ large decrease in color \\
\hline $3=$ blisters anderosion & $3=$ no color & nested cells & $3=$ no color \\
\hline
\end{tabular}

\subsubsection{Measuring Serum Cytokines, MMPs, and Lipocalin-2 Levels}

Approximately $5 \mathrm{~mL}$ of whole blood was collected from the vena cava at euthanization, and the serum was separated by centrifugation at $2000 \mathrm{rpm}$ for $15 \mathrm{~min}$. Serum concentrations of TNF- $\alpha$, IL-1 $\beta$, IL-6, MMP-2, MMP-3, MMP-7, MMP-8, MMP-9, MMP-13, and lipocalin-2 were measured using sandwich enzyme-linked immunosorbent assays (ELISAs). TNF- $\alpha$ (ab46070, Abcam, Cambridge, UK), IL-1 $\beta$ (ab100768, Abcam), IL-6 (ab119548, Abcam), IFN- $\gamma$ (ab46107, Abcam), MMP-2 (ab213910, Abcam), MMP-3 (LS-F5516, LSBio, Seattle, WA, USA), MMP-7 (LS-F5514, LSBio), MMP-8 (ab100779, Abcam), MMP-9 (LSF32423, LSBio), MMP-13 (ab221839, Abcam), and lipocalin-2 (ab119602, Abcam) for rats were used in this measurement. The assays were performed according to the manufacturer's instructions, and the absorbance of the contents of each well was measured at $450 \mathrm{~nm}$ using a microplate reader (Molecular Devices, Silicon Valley, CA, USA).

2.2.6. Measuring mRNA Expressions of Cytokines and MMPs in the Cartilage of OA Rats

RNA was isolated from the cartilages with synovial membrane of intact or surgically induced OA rats using the RNeasy Mini Plus Kit (74106, Qiagen, Valencia, CA, USA). Onestep quantitative polymerase chain reaction (qPCR) was carried out using Quantifast SYBR Green RT-PCR kit (204156, Qiagen) by a one-step cycler. Amplification was performed according to the conditions using the BioRad CFX-96 real-time system (BioRad, Hercules, CA, USA). All results were normalized to glyceraldehyde 3-phosphate dehydrogenase (GAPDH) expression. The primer information (Qiagen) used for qPCR is shown in Table 2. 
Table 2. Primer information for gene expression in qPCR experiment.

\begin{tabular}{cccc}
\hline Gene Symbol & Catalog Number & Detected Transcript(s) & Amplicon Length \\
\hline GAPDH & QT00199633 & NM_017008 & $149 \mathrm{bp}$ \\
IL-6 & QT00182896 & NM_012589 & $128 \mathrm{bp}$ \\
IL-18 & QT02459506 & XM_001070641 & $105 \mathrm{bp}$ \\
MMP-2 & QT00996254 & NM_031054 & $103 \mathrm{bp}$ \\
MMP-3 & QT00189308 & NM_133523 & $82 \mathrm{bp}$ \\
MMP-9 & QT00178290 & $149 \mathrm{bp}$ \\
\hline
\end{tabular}

\subsection{Statistical Analysis}

All data are expressed as mean \pm SEM. One-way ANOVA (one-way analysis of variance) was performed using Statistical Package for the Social Sciences (SPSS ver. 24, IBM Corp, Armonk, NY, USA). NC group was compared to the CON group by Student's $t$ test, and a Duncan's multiple-range test was conducted to determine significant differences among the groups. Significant difference was considered at $p<0.05$.

\section{Results}

\subsection{Characterization of Flavonoids in Plebeian Sage and Its Extract}

Plebeian sage leaf contains $77.8 \mathrm{mg}$ of flavonoids, and its extract (PS) contains $365.5 \mathrm{mg}$ flavonoids per each dry matter (g). Six representative compounds consisting of flavone (5) and flavanone (1) derivatives were tentatively identified from the leaf and PS through positive ionized mass fragmentation using UPLC-DAD-QToF/MS analysis (Table 3). The current positive ionized pattern of these compounds provides additional sodium $\left(\mathrm{Na}^{+}, m / z 23\right)$ and potassium $\left(\mathrm{K}^{+}, m / z 39\right)$ adduct ions with basic protonated molecules $[\mathrm{M}+\mathrm{H}]^{+}$that can help to determine the parent ion. The conjugations with glucose moiety (162 Da) were the $7-\mathrm{OH}$ position of their corresponding aglycones ([M+H-glucose $\left.]^{+}\right)$such as 6-hydroxyluteolin ( $m / z 303), 5,7,3^{\prime}, 4^{\prime}$-tetrahydroxy-6-methoxyflavanone $(\mathrm{m} / \mathrm{z} 319)$, luteolin $(m / z 287)$, nepetin $(m / z 317)$ and hispidulin $(m / z 301)$.

Table 3. Characterization of isolated flavone and flavanone derivatives from Plebeian sage leaf and its extract (PS).

\begin{tabular}{|c|c|c|c|}
\hline \multirow{2}{*}{ Compounds } & \multirow{2}{*}{$\begin{array}{c}\text { ESI(+)-QToF/MS } \\
\text { Fragmentation of }[\mathrm{M}+\mathrm{H}]^{+}(\mathrm{m} / \mathrm{z})\end{array}$} & \multicolumn{2}{|c|}{ Contents (mg/g Dry Matters) } \\
\hline & & Leaf & PS \\
\hline 6-hydorxyluteolin 7-O-glucoside & $487,465,303$ & $13.5 \pm 0.4$ & $65.9 \pm 4.6$ \\
\hline $\begin{array}{c}\text { 5,7,3', } 4^{\prime} \text {-tetrahydroxy-6-methoxyflavanone } \\
\text { 7-O-glucoside (naasanone) }\end{array}$ & $503,481,319$ & $9.4 \pm 0.2$ & $53.4 \pm 1.3$ \\
\hline luteolin 7-O-glucoside (cynaroside) & $471,449,287$ & $11.3 \pm 0.4$ & $62.8 \pm 1.3$ \\
\hline nepetin $7-O$-glucoside (nepitrin) & $501,479,317$ & $23.5 \pm 0.6$ & $78.3 \pm 1.9$ \\
\hline hispidulin 7-O-glucoside (homoplantaginin) & $485,463,301$ & $19.5 \pm 0.4$ & $104.8 \pm 2.4$ \\
\hline hispidulin & $339,323,301$ & $0.6 \pm 0.1$ & $1.3 \pm 0.1$ \\
\hline Total & & $77.8 \pm 1.9$ & $365.5 \pm 9.1$ \\
\hline
\end{tabular}

All samples analyzed in positive ESI-ionization mode $\left(m / z[\mathrm{M}+\mathrm{H}]^{+}\right)$of ToF-MS; $[\mathrm{M}+\mathrm{Na}]^{+}$and $[\mathrm{M}+\mathrm{K}]^{+}$adducts are presented. Bold font indicates parent ion $\left([\mathrm{M}+\mathrm{H}]^{+}\right)$of flavonoid structures. Each content calculated as means $\pm \mathrm{SD}$ $(\mathrm{n}=3)$ using internal standard (6-methoxyluteolin).

Among these glycosides (mg/g dry matter of leaf), 6-hydorxyluteolin 7-O-glucoside (13.5 g), cymaroside (11.3 g), nepitrin (23.5 g) and homoplantaginin (19.5 g) were found as major constituents. Especially, 5,7,3', $4^{\prime}$-tetrahydroxy-6-methoxyflavanone 7-O-glucoside is a new flavanone glycoside (naasanone, $9.4 \mathrm{~g}$ ). In the PS, most flavonoids increased by more than three times compared to those in the Plebeian sage leaf. PS contains 6-hydorxyluteolin 7-O-glucoside (65.9 g), naasanone (53.4 g), cymaroside (62.8 g), nepitrin (78.3 g) and homoplantaginin (104.8 g) as major constituents of flavonoids. 


\subsection{Animal Experiments}

3.2.1. Effects of Treatment with PS on Body Weight and Food Efficiency Ratio

At the beginning of this experiment, there was no significant difference in body weight among all groups of the sham and OA rats. Body weight, body weight gain, and food intake were similar in all experimental groups (Table 4).

Table 4. Effects of PS on the final body weight, body weight gain, and food intake in the surgically induced OA rats.

\begin{tabular}{|c|c|c|c|c|}
\hline \multirow{2}{*}{ Groups } & \multicolumn{2}{|c|}{ Body Weight (g) } & \multirow{2}{*}{$\begin{array}{l}\text { Weight Gain } \\
\text { (g) }\end{array}$} & \multirow{2}{*}{$\begin{array}{l}\text { Food Intake } \\
\quad \text { (g/rat) }\end{array}$} \\
\hline & 0 Week & 12th Week & & \\
\hline $\mathrm{CON}$ & $374.6\left(6.1^{\mathrm{NS}}\right)$ & $615.6\left(17.7^{\mathrm{NS}}\right)$ & $241.0\left(16.4^{\mathrm{NS}}\right)$ & $1560.0\left(38.5^{\mathrm{NS}}\right)$ \\
\hline $\mathrm{NC}$ & $371.1(10.7)$ & $610.8(10.8)$ & $239.7(9.8)$ & $1594.7(44.3)$ \\
\hline PC & $379.7(5.4)$ & $613.2(15.0)$ & $233.6(15.0)$ & $1534.1(6.4)$ \\
\hline PS1 & $374.8(14.8)$ & $622.3(18.2)$ & $247.5(14.0)$ & $1566.1(58.3)$ \\
\hline PS2 & $369.7(7.2)$ & $620.5(19.4)$ & $250.9(12.4)$ & $1544.0(84.5)$ \\
\hline
\end{tabular}

CON: normal sham control; NC: negative control; PC: positive control, which was subcutaneously injected with diclofenac sodium salt at $2 \mathrm{mg} / \mathrm{kg}$ BW in sterilized saline into the dorsal skin; PS1: PS at $100 \mathrm{mg} / \mathrm{kg} \mathrm{BW}$; PS2: PS at $300 \mathrm{mg} / \mathrm{kg}$ BW. The data were presented as the mean \pm S.E. $(n=4 \sim 5 /$ group$) . ~{ }^{\text {NS }}$ Mean values are not significantly different $(p<0.05)$ among groups by Duncan's multiple range test.

3.2.2. Effects of PS on the Articular Surface Lining Cartilage with SM on the Knee Joint Tissues in OA Rats

The representative general H\&E stained histopathological profiles of knee joint tissues are shown in Figure 2. This figure shows that PS affected histopathological profiles of knee joint tissues in rats with surgically induced OA compared to those of the NC group. As shown in the NC group (Figure 2b), significant decreases in the femur and tibia AC thickness and increases on the SM epithelial thicknesses and inflammatory cell numbers infiltrated around the SM as compared to those of the normal CON group (Figure 2a) were found, suggesting classic OA histopathological lesions in the NC group. However, Figure 2d,e showed that PS1 and PS2 significantly increased the femur and tibia AC thickness while they decreased the SM epithelial thicknesses and inflammatory cell numbers in a dosedependent manner.

Table 5 shows the histomorphometrical results on the articular surface lining cartilage and synovial membrane. Mean femur AC thickness in OA control NC group was reduced to $40.6 \%$ as compared with that of the normal CON group, but the value was improved as $209.7 \%, 220.2 \%$, and $233.9 \%$ in PC, PS1, and PS2 groups compared to that of the NC group, respectively. Mean tibia AC thickness in NC was also changed at $43.8 \%$ as compared with that of the CON group, but the level increased to $199.2 \%, 176.5 \%$, and $213.3 \%$ in PC, PS1, and PS2 groups compared to that of the NC group, respectively. Mean SM epithelial thicknesses of the knee joints in the NC group increased to 309.9\% as compared with that of the CON group, but the value decreased to $52.2 \%, 49.8 \%$, and $44.6 \%$ in the PC, PS1, and PS2 groups, respectively, as compared with that of the NC group. In the NC group, mean numbers of inflammatory cells infiltrated around SM of the knee joints increased by $400.0 \%$ as compared with that of the CON group, but the level changed as $48.8 \%, 35.2 \%$, and $25.9 \%$ in the PC, PS1, and PS2 groups, respectively, compared with that of the NC group (Table 5). Thus, PS significantly improved histomorphometrical values of the articular surface lining cartilage and synovial membrane, and the effectiveness was similar or higher than that of the PC group treated with diclofenac sodium salt.

\subsubsection{Effects of PS on the Mankin Score of the Knee Joint Tissues}

SO-stained histopathology of knee joint tissues in OA rats are shown in Figure 3. In the NC group, significant surface cartilage damages and increased clone formations in both femur and tibia AC were detected. However, PS improved surface cartilage condition and decreased clone formations that affected the histopathological characteristics of the 
joints and synovial tissues of the knee joint tissues in the rats with surgically induced OA compared to those of the NC.
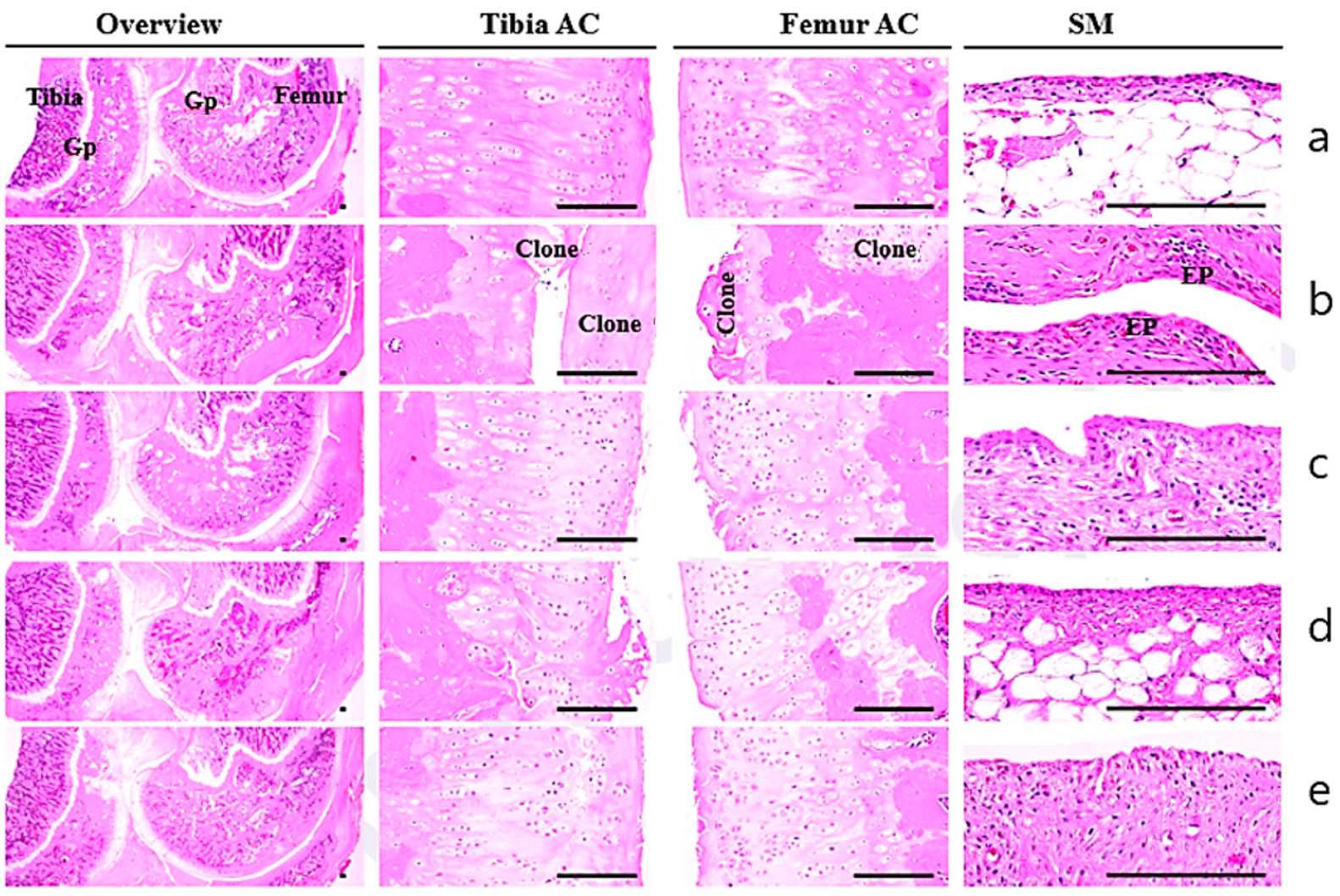

Figure 2. The effects of PS on H\&E-stained histopathological profiles of knee joint tissues in rats with surgically induced OA $(40 \times)$. (a) CON: normal sham control; (b) NC: negative control; (c) PC: positive control, rats treated with diclofenac sodium salt at $2 \mathrm{mg} / \mathrm{kg} \mathrm{BW}$ in sterilized saline into the dorsal skin; (d) PS1: PS at $100 \mathrm{mg} / \mathrm{kg}$ BW; (e) PS2: PS at $300 \mathrm{mg} / \mathrm{kg}$ BW. Gp: growth plate; EP: epithelium; scale bars $=160 \mu \mathrm{m}$.

Table 5. The effects of PS on histomorphometrical values of the articular surface lining cartilage and synovial membrane of the knee joint tissues in the OA rats.

\begin{tabular}{|c|c|c|c|c|}
\hline \multirow[b]{2}{*}{ Groups } & \multicolumn{3}{|c|}{ Articular Surface Lining Cartilage } & \multirow{2}{*}{$\begin{array}{c}\text { Synovial Membrane } \\
\text { Mean Inflammatory } \\
\text { Cells (Cells } / \mathrm{mm}^{2} \text { ) }\end{array}$} \\
\hline & Femur Thickness $(\mu \mathrm{m})$ & Tibia Thickness $(\mu \mathrm{m})$ & $\begin{array}{l}\text { Mean Epithelial } \\
\text { Thickness }(\mu \mathrm{m})\end{array}$ & \\
\hline $\mathrm{CON}$ & $430.0\left(39.5^{\mathrm{a}}\right)$ & $467.2\left(49.3^{\mathrm{a}}\right)$ & $8.1\left(0.2^{b}\right)$ & $41.5\left(31.7^{\mathrm{c}}\right)$ \\
\hline NC & $174.4\left(25.7^{* * *, \mathrm{~b}}\right)$ & $204.8\left(19.8^{* * *, \mathrm{~b}}\right)$ & $25.1\left(0.6^{* * *, a}\right)$ & $166.0\left(15.9^{* * *, \mathrm{a}}\right)$ \\
\hline PC & $365.7\left(47.9^{\mathrm{a}}\right)$ & $408.0\left(28.3^{\mathrm{a}}\right)$ & $13.1\left(2.8^{b}\right)$ & $81.0\left(10.7^{b}\right)$ \\
\hline PS1 & $384.0\left(57.8^{\mathrm{a}}\right)$ & $361.5\left(33.4^{\mathrm{a}}\right)$ & $12.5\left(2.4^{b}\right)$ & $58.5\left(3.1^{b c}\right)$ \\
\hline PS2 & $408.0\left(53.5^{a}\right)$ & $437.0\left(30.9^{a}\right)$ & $11.2\left(2.0^{b}\right)$ & $43.0\left(3.3^{c}\right)$ \\
\hline
\end{tabular}

CON: normal sham control; NC: negative control; PC: positive control; PS1: PS at $100 \mathrm{mg} / \mathrm{kg}$ BW; PS2: PS at $300 \mathrm{mg} / \mathrm{kg}$ BW. The data were analyzed by one-way ANOVA using SPSS software and presents as the mean \pm S.E. ( $\mathrm{n}=4 \sim 5$ /group). NC group is significantly different from the CON group at ${ }^{* * *} p<0.001$ by Student's $t$ test. ${ }^{a-c}$ Mean values with different letters are significantly different $(p<0.05)$ among groups by Duncan's multiple range test. 
Overview
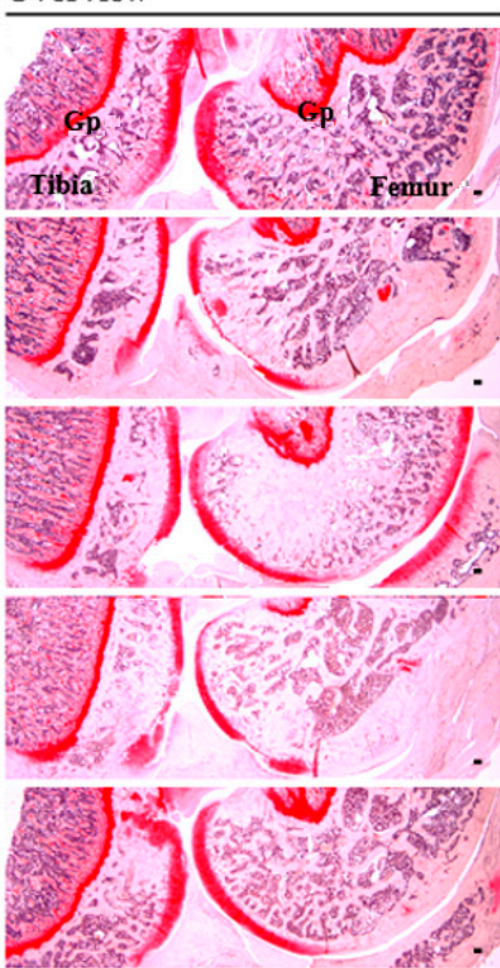

Tibia AC

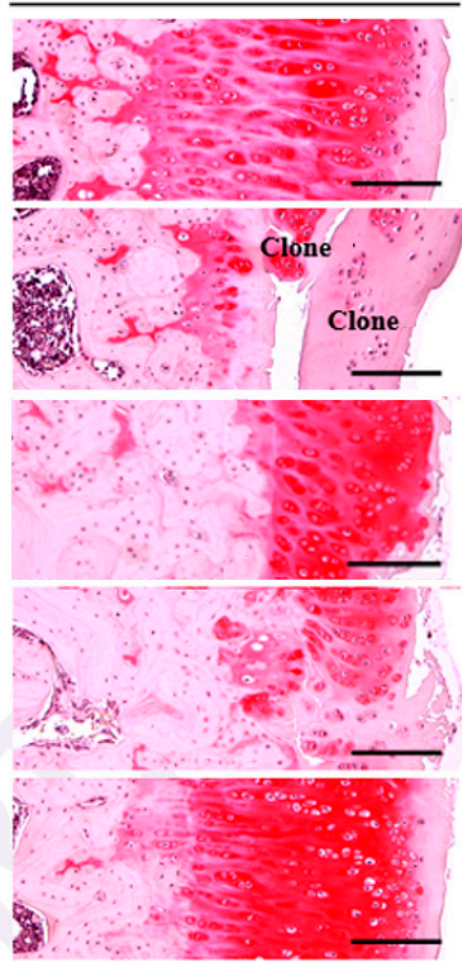

Femur AC

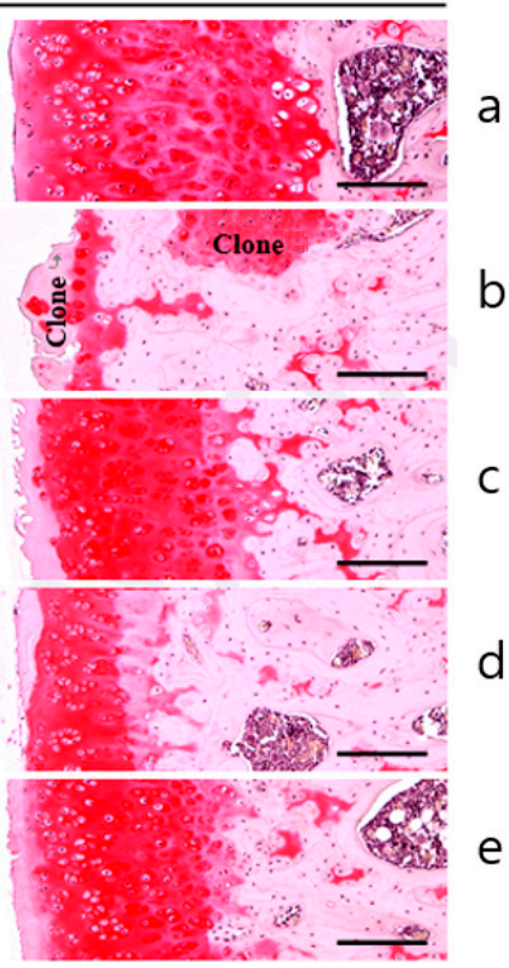

Figure 3. The effects of PS- on SO-stained histopathological characteristics of joints and synovial tissues of knee joint tissues in surgically induced OA rats $(40 \times)$. (a) CON: normal sham control; (b) NC: negative control; (c) PC: positive control, rats treated with diclofenac sodium salt at $2 \mathrm{mg} / \mathrm{kg}$ BW in sterilized saline into the dorsal skin; (d) PS1: PS at $100 \mathrm{mg} / \mathrm{kg}$ BW/day; (e) PS2: PS at $300 \mathrm{mg} / \mathrm{kg} \mathrm{BW} /$ day. Gp; growth plate, EP; epithelium, scale bars $=160 \mu \mathrm{m}$.

In Table 6, the OA control (NC) showed marked increases in surface cartilage damages and decreases in chondrocytes, clone formations, and Safranin O stain intensities on both femur and tibia AC. Consequently, significant $(p<0.01)$ increases in the Mankin scores were detected in the NC group as compared with those in the normal CON group. However, the Mankin scores of femoral and tibial AC were lower in PS groups than those of the NC group, in a dose-dependent manner. Totalized Mankin score of the knee joints in OA control NC group was changed by $864.0 \%$ as compared with that of the intact control CON group, but they were reduced as 50.9\%, 48.6\%, and 23.1\% in PC, PS1, and PS2 groups, respectively, as compared with that of the NC group.

Table 6. The effects of PS on histomorphometrical data obtained by the Mankin scoring systems on the knee joint tissues of OA rats.

\begin{tabular}{|c|c|c|c|c|c|}
\hline Groups & $\begin{array}{l}\text { Surface Condition } \\
\quad(\operatorname{Max}=3)\end{array}$ & $\begin{array}{l}\text { Hypocellularity } \\
(\operatorname{Max}=3)\end{array}$ & $\begin{array}{l}\text { Clones } \\
(\operatorname{Max}=3)\end{array}$ & $\begin{array}{l}\text { Stain Intensity } \\
\quad(\operatorname{Max}=3)\end{array}$ & $\begin{array}{c}\text { Totalized Final Score } \\
(\operatorname{Max}=12)\end{array}$ \\
\hline $\mathrm{CON}$ & $0.50\left(0.29^{\mathrm{c}}\right)$ & $0.25\left(0.25^{\mathrm{cd}}\right)$ & $0.00\left(0.00^{\mathrm{c}}\right)$ & $0.50\left(0.29^{c}\right)$ & $1.25\left(0.48^{\mathrm{c}}\right)$ \\
\hline $\mathrm{NC}$ & $2.80\left(0.00^{* * *, a}\right)$ & $2.40\left(0.29^{* * *, a}\right)$ & $3.00\left(0.00^{* * *, a}\right)$ & $2.60\left(0.25^{* * *, a}\right)$ & $10.80\left(0.48^{* * *, a}\right)$ \\
\hline PC & $1.25\left(0.25^{b c}\right)$ & $1.25\left(0.25^{b}\right)$ & $1.25\left(0.48^{b}\right)$ & $1.75\left(0.25^{\mathrm{ab}}\right)$ & $5.50\left(0.96^{b}\right)$ \\
\hline PS1 & $1.75\left(0.48^{b}\right)$ & $1.00\left(0.41^{b c}\right)$ & $1.25\left(0.25^{b}\right)$ & $1.25\left(0.48^{b c}\right)$ & $5.25\left(1.25^{b}\right)$ \\
\hline PS2 & $1.00\left(0.00^{b c}\right)$ & $0.00\left(0.00^{\mathrm{d}}\right)$ & $0.50\left(0.29^{c}\right)$ & $1.00\left(0.00^{b c}\right)$ & $2.50\left(0.29^{c}\right)$ \\
\hline
\end{tabular}

CON: normal sham control; NC: negative control; PC: positive control, which was subcutaneously injected with diclofenac sodium salt at $2 \mathrm{mg} / \mathrm{kg}$ BW in sterilized saline into the dorsal skin; PS1: PS at $100 \mathrm{mg} / \mathrm{kg}$ BW; PS2: PS at $300 \mathrm{mg} / \mathrm{kg}$ BW. The data are presented as the mean \pm S.E. ( $n=4 \sim 5 /$ group). NC group is significantly different from the CON group at ${ }^{* * *} p<0.001$ by Student's $t$ test. ${ }^{\text {a-d }}$ Mean values with different letters are significantly different $(p<0.05)$ among groups by Duncan's multiple range test. 


\subsubsection{Effects of PS on Serum Inflammatory Cytokines Levels}

The results indicate that there was a clear increase in the levels of IL-1 $\beta$, IL-6, and TNF$\alpha$ in the surgically induced OA, NC group $(p<0.01)$ compared to the CON group (Figure 4$)$. However, daily treatment with PS at a dose of 100 or $300 \mathrm{mg} / \mathrm{kg}$ BW significantly decreased the release of IL-1 $\beta$, IL- 6 , and TNF- $\alpha$ into the serum $(p<0.05$ or $p<0.01)$ compared to those of the NC group. PS group showed significantly reduced serum IL-1 $\beta$ level compared to the NC group. Furthermore, the IL- $1 \beta$ level of the PS group was reduced over $34 \%$ compared to that of the PC group, without significant differences between the groups. In the PS groups, serum IL-6 levels also significantly decreased compared to the NC group, and the effect was compared to the PC group. The serum IFN- $\gamma$ levels tend to decrease in the PC and PS groups, although there was no significant difference found $(2.4 \sim 2.6 \mathrm{pg} / \mathrm{mL})$.

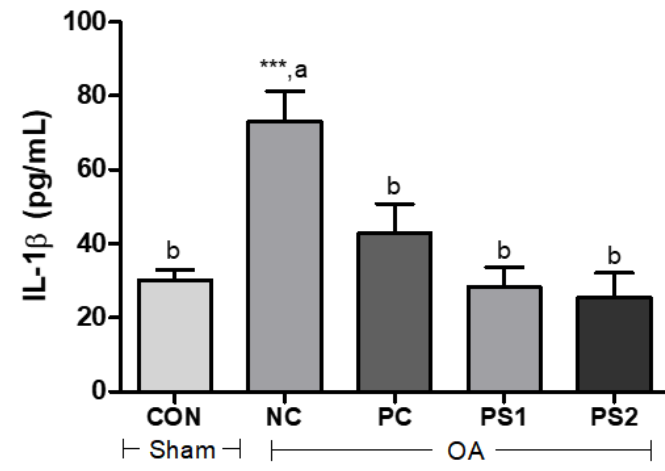

(a)

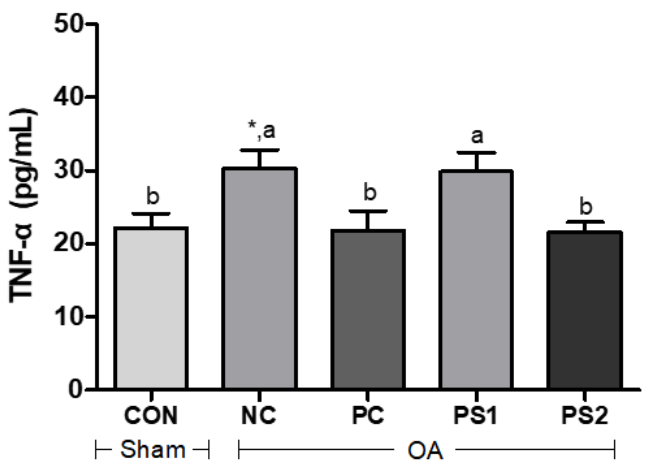

(c)

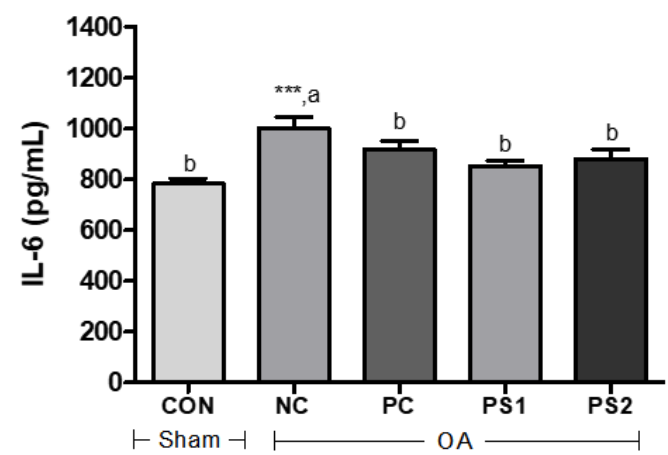

(b)

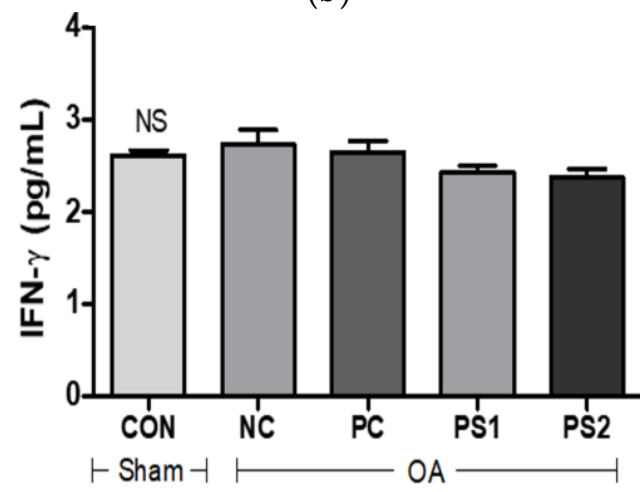

(d)

Figure 4. Effects of PS on serum inflammatory cytokine (a) IL-1 $\beta$, (b) IL-6, (c) TNF- $\alpha$, and (d) IFN- $\gamma$ levels in OA rats. CON: normal sham control; NC: negative control; PC: positive control; PS1: PS at $100 \mathrm{mg} / \mathrm{kg}$ BW; PS2: PS at $300 \mathrm{mg} / \mathrm{kg}$ BW. The data are presented as the mean \pm SE ( $\mathrm{n}=4 \sim 5 /$ group). NC group was significantly different from the CON group at ${ }^{*} p<0.05,{ }^{* * *} p<0.001$ by Student's $t$ test. NS Not significantly different among groups. ${ }^{a, b}$ Mean values with different letters are significantly different $(p<0.05)$ among groups by Duncan's multiple range test.

\subsubsection{Effects of PS on Serum MMPs Levels}

Serum MMPs (MMP-2, MMP-3, MMP-7, MMP-8, MMP-9, MMP-13), and lipocalin-2 levels were evaluated in the OA rats and are presented in Figure 5. The serum MMP-2, MMP-7, MMP-8, MMP-9, MMP-13, and lipocalin-2 levels were higher in the OA NC group compared with those in the normal CON group. MMP-2 level decreased in the PS groups, showing a dose-dependent manner, and a significant difference was found in the PS2 group compared to the NC group (Figure 5a). Serum MMP-3 level increased in the OA experimental animals compared to the CON group, and the levels were lower in the PS groups $(p>0.05)$, although there was no significant difference among the experimental animals. Serum MMP-7 and 8 levels were higher in the OA animals compared to those of the normal CON group. However, the values decreased in the PC and PS groups. PS 
lowered the serum MMP-7 level in a dose-dependent manner. PS's effect on the MMP-8 was comparable to the diclofenac sodium salt, which was used as a positive control. Serum MMP-9 and 13 values increased in the OA rats compared with the CON group. However, the values significantly decreased in the PC and PS groups compared to the NC group. The lipocalin-2 level, which was increased in the OA rats, was lowered by PS. Moreover, MMP-2, MMP-7, and lipocalin-2 levels more effectively decreased in the groups administered with PS at $300 \mathrm{mg} / \mathrm{kg}(p<0.01)$ than in the PC group as a positive control. Generally, PS affected the serum MMPs and lipocalin-2 levels and MMP-2, 7, and lipocalin-2 levels decreased in a dose-dependent manner.

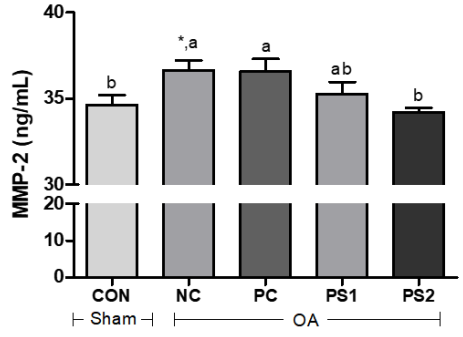

(a)

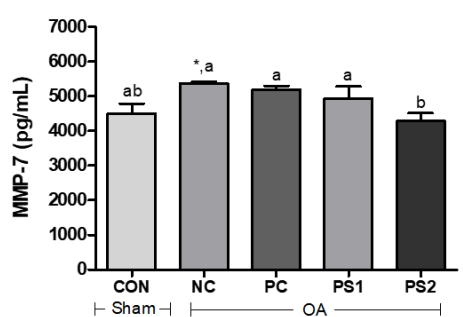

(c)

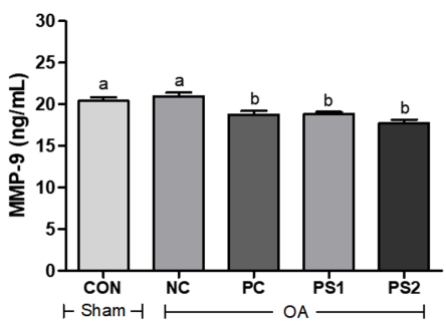

(e)

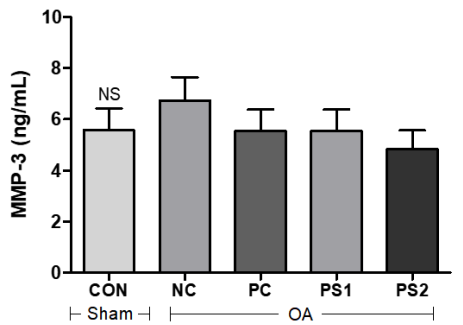

(b)

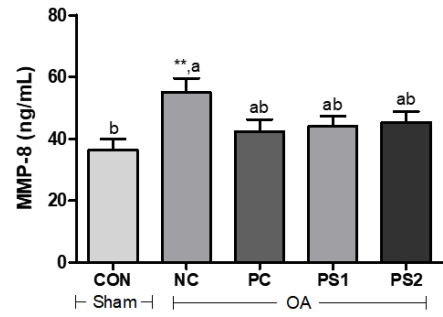

(d)

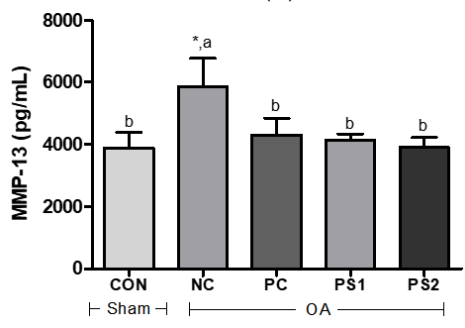

(f)

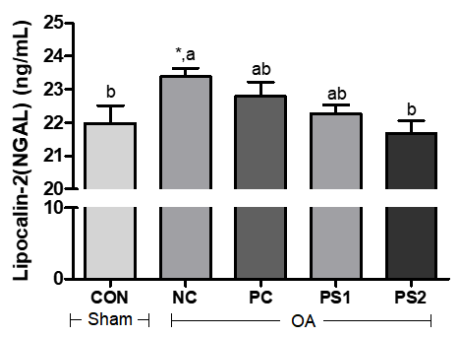

(g)

Figure 5. Effects of PS on serum MMPs (a) MMP-2, (b) MMP-3, (c) MMP-7, (d) MMP-8, (e) MMP-9, (f) MMP-13, and (g) lipocalin-2 levels in OA rats. CON: normal sham control; NC: negative control; PC: positive control; PS1: PS at $100 \mathrm{mg} / \mathrm{kg}$ BW; PS2: PS at $300 \mathrm{mg} / \mathrm{kg}$ BW. The data are presented as the mean $\pm S E$ ( $n=4 \sim 5$ /group). NC group was significantly different from CON group at $*<<0.05$, ${ }^{* *} p<0.01$ by Student's $t$ test. NS Not significantly different among groups. ${ }^{\mathrm{a}, \mathrm{b}}$ Mean values with different letters are significantly different $(p<0.05)$ among groups by Duncan's multiple range test. 


\subsubsection{Effects of PS on mRNA Expressions of Cytokines IL-6 and IL-18 in Cartilage}

Figure 6 shows higher levels of IL- 6 and IL-18 in the cartilage with synovial membrane of the NC group $(p<0.01)$ compared to the normal CON group. However, daily treatment with PS at a dose of 100 or $300 \mathrm{mg} / \mathrm{kg}$ decreased the release of IL-6 and IL-18 expression in the cartilage. The significant difference was found in the IL- 6 and IL-18 $(p<0.01$ or $p<0.001)$ compared to the NC group. The mRNA expression level of cytokine IL- 6 was comparable to the diclofenac sodium salt for the PC group. Furthermore, the mRNA expression level of cytokine IL-18 was significantly and effectively reduced in the PS group versus the NC and PC groups.

\subsubsection{Effects of PS on MMPs Expression in Cartilage with Synovial Membrane}

The expression levels of MMP-2, MMP-3, and MMP-9 in the cartilage with synovial membrane of OA rats are shown in Figure 7. They were significantly higher in the NC group compared with those of the CON group. PC and PS groups decreased the expression levels of MMP-2, MMP-3, and MMP-9 in cartilage. PS2 treatment effectively affected the MMP expression levels of OA rats and showed a similar or higher effect than the diclofenac sodium salt used for the PC group.

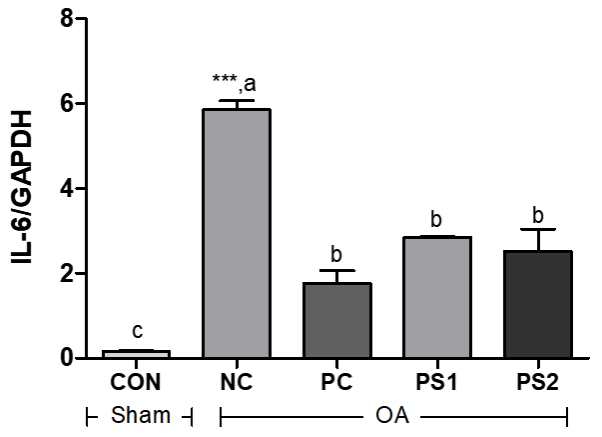

(a)

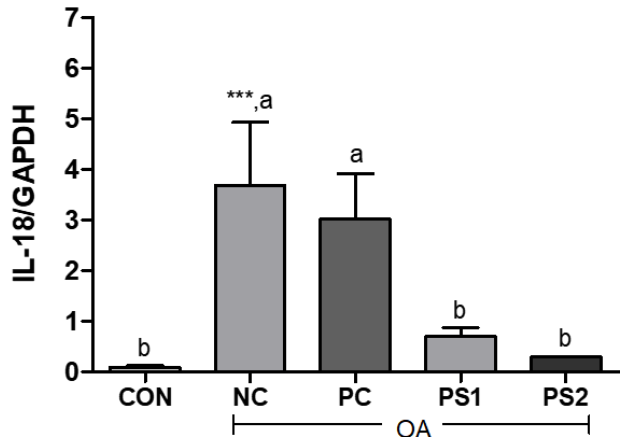

(b)

Figure 6. Effects of PS on cytokines expression in the cartilage with synovial membrane of OA rats. (a) IL-6 and (b) IL-18. Data are expressed as the mean \pm SE ( $n=4 /$ group). CON: normal sham control; NC: negative control; PC: positive control; PS1: PS at $100 \mathrm{mg} / \mathrm{kg}$ BW; PS2: PS at $300 \mathrm{mg} / \mathrm{kg}$ BW. NC group was significantly different from the CON group at ${ }^{* * *} p<0.001$ by Student's $t$ test. ${ }^{a-c}$ Mean values with different letters are significantly different $(p<0.05)$ among groups by Duncan's multiple range test.

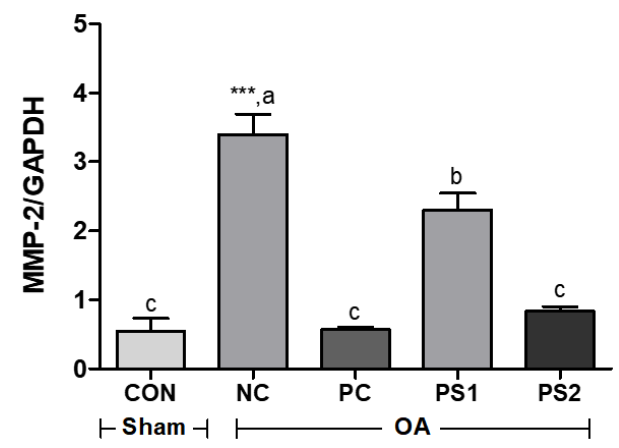

(a)

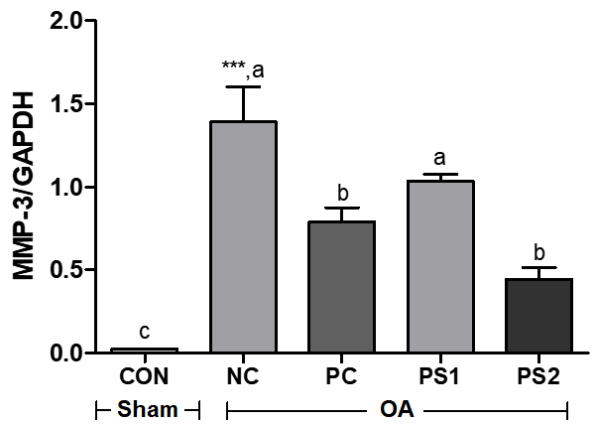

(b)

Figure 7. Cont. 


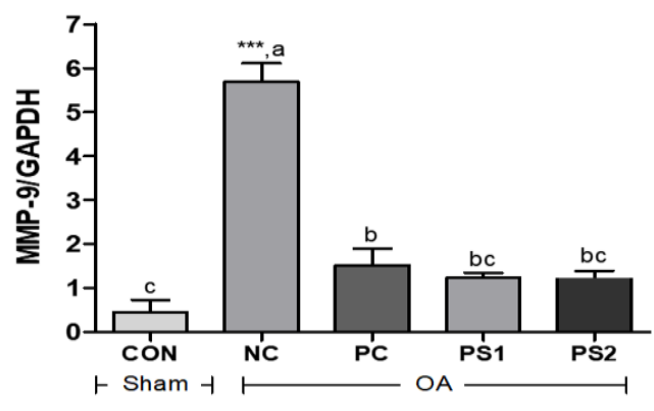

(c)

Figure 7. Effects of PS on cytokines expression in the cartilage with synovial membrane of OA rats. (a) MMP-2, (b) MMP-3, and (c) MMP-9. Data are expressed as the mean $\pm \mathrm{SE}$ ( $\mathrm{n}=4$ /group). CON: normal sham control; NC: negative control; PC: positive control; PS1: PS at $100 \mathrm{mg} / \mathrm{kg}$ BW; PS2: PS at $300 \mathrm{mg} / \mathrm{kg}$ BW. NC group was significantly different from the CON group at ${ }^{* * *} p<0.001$ by Student's $t$ test. ${ }^{\mathrm{a}-\mathrm{c}}$ Mean values with different letters are significantly different $(p<0.05)$ among groups by Duncan's multiple range test.

\section{Discussion}

The primary approach in the clinical treatment of OA involves the use of nonsteroidal anti-inflammatory drugs (NSAIDs), analgesics, and hyaluronan, which allow for symptomatic relief but provide no apparent disease-modifying effects [3]. In some instances, NSAIDs may even have deleterious effects, as they inhibit the synthesis of proteoglycan, which plays a crucial role in maintaining the functions of the cartilage. Therefore, there is a critical need to develop alternative agents that can prevent the destruction of cartilage or stimulate their proper repair [6,8].

$\mathrm{OA}$ is the most prevalent articular disease in the elderly [1] and is characterized by loss of articular cartilage components, leading to tissue destruction and hypocellularity, eventually resulting in loss of joint function $[19,27]$. Alternative agents that can prevent the destruction of cartilage or stimulate its proper repair are needed [6] due to the deleterious effects of NSAIDs [3]. In this study, anti-arthritis effects were evaluated from PS with high anti-oxidative [30] and anti-inflammatory effects [32]. The active components of PS comprise flavonoids and phenolic acid [34,35]. These materials are known to have antioxidant and anti-inflammatory effects, and the inflammation may be controlled by reducing nitric oxide generation [39].

Mankin's 12-point histopathological grading system of cartilage deterioration is based on cartilage surface damage, the number of chondrocytes, and Safranin O staining. In this study, normal cartilage was scored as 0 in the control CON group; the most severe case of cartilage deterioration had a high score of 10.8 in the NC group (Table 5) as shown in the previous report [22]. OA control rats (NC) showed marked increases in surface cartilage damage, decreases in chondrocytes, and clone formations on both femur and tibia AC when compared with those of normal control rats (CON). In addition, NC also showed significant decreases in the mean femur and tibia AC thicknesses, and increases in SM epithelial thicknesses and inflammatory cell numbers infiltrated around the SM/IFP as compared to those of the $\mathrm{CON}$, suggesting classic OA histopathological lesions. Inflammation and fibrosis presented in SM/IFP. However, these histopathological surgically induced histopathological OA lesions were obviously and most significantly inhibited by PC and PS treatments in a dose-dependent manner. PS2 showed more favorable inhibitory effects than those of the commercial reference (PC), and PS1 was comparable to the anti-OA effects of PC (Figure 3, Table 5). In the previous trial using a mixture of dried pomegranate concentrate powder, eucommiae cortex, and achyranthis radix, this improved the decreases in $\mathrm{AC}$ thickness and the number of chondrocytes detected in OA rats [22]. OA is the most common clinical syndrome of joint pain accompanied by varying degrees of functional limitation [4]. PS inhibited the inflammatory response in human rheumatoid synovial 
fibroblasts and a murine model of arthritis [33]. Thus, effects of PS on joint pain in a rat model of surgically induced OA and comparisons of the mechanisms in different arthritis models should be measured in future studies [40].

$\mathrm{OA}$ is a debilitating disease that affects the $\mathrm{AC}$ and subchondral bone, and inflammation is closely involved in all steps of OA progression [39]. The inflammatory factors TNF- $\alpha$, IL- $1 \beta$, and IL- 6 contribute to OA progression [41]. OA-induced rabbits exhibited significant decreases in AC thickness of the femur and tibia. It is also reported that the number of chondrocytes significantly increased synovial IL-1 $\beta$, IL-6, and TNF- $\alpha$ levels and significantly increased numbers of femoral and tibial subchondral IL- $1 \beta$ and TNF$\alpha$-immunolabeled cells [42]. In this trial, treatment of PS favorably inhibited surgically induced OA through anti-inflammatory and AC preserving effects (Figure 3). The inflammatory cytokine (IL-1 $\beta$ IL- 6, TNF- $\alpha$ ) levels increased in the NC group versus those of the normal control CON group. Conversely, these OA-induced symptoms of inflammation were significantly inhibited by 12 weeks of supplement with PS (100 and $300 \mathrm{mg} / \mathrm{kg}$ body weight). PS decreased the release of IL-1 $\beta$, IL- 6 , and TNF- $\alpha$ into the serum of OA rats. These findings represent reliable evidence that PS has favorable anti-inflammatory effects on surgically induced OA rats, and these results are consistent with the report showing a strong correlation between low inflammatory levels and anti-osteoarthritis effects in animals supplemented with functional foods $[22,25]$.

MMPs are involved in the degradation of the ECM [42], although their expression can be suppressed by metalloproteinase inhibitors [43]. The MMPs are reliable predictors of cartilage loss during the development of OA [44], and their increase has been reported in the synovium and chondrocytes of surgically induced OA models [45]. Lipocalin-2 is believed to play a significant functional role in OA cartilage [46] as a biomarker for cartilage degradation in arthritic disease [47], although Choi and Chun suggested that its upregulation in osteoarthritic cartilage is not necessary for cartilage destruction in mice [16]. In this study, we found that PS decreased serum MMP-2, MMP-7, MMP-9, MMP-13, and lipocalin-2 levels when administered at a dose of 100 or $300 \mathrm{mg} / \mathrm{kg}(p<0.05)$ compared with those of the NC group. After treating the rats with PC, weak effects on the serum MMP-2, $-3,-7,-8$, and lipocalin-2 levels of OA rats were observed $(p>0.05)$. It is interesting that PS improved the biomarkers such as MMP-2, -7, and lipocalin-2 in a dose-dependent manner and was more effective than diclofenac sodium salt for the PC group. Furthermore, not only Plebeian sage extracted with $95 \% v / v \mathrm{EtOH}$ at $70{ }^{\circ} \mathrm{C}$ [33] but also Plebeian sage extracted with $50 \% v / v \mathrm{EtOH}$ at room temperature effectively inhibited osteoarthritis. This is a great news to customers and health food producers with its low producing price and higher safety. Thus, the PS used in this study may be used widely for osteoarthritis treatment with lower prices and improved safety.

iNOS is induced by pro-inflammatory cytokines and is involved in high levels of NO production during the inflammatory process $[48,49]$. NF- $\kappa$ B proteins constitute a family of transcription factors stimulated by pro-inflammatory cytokines, chemokines, stressrelated factors, and ECM degradation products. The activated NF- $\kappa$ B molecules trigger the expression of genes that induce destruction of the articular joint [10]. The activation of stressand inflammation-induced signaling, transcriptional, and posttranscriptional events may cause a phenotypic shift, apoptosis, and aberrant expression of inflammation-related genes, including catabolic genes [25]. These include nitric oxide synthase (NOS)-2, cyclooxygenase (COX)-2, and several matrix metalloproteinases (MMPs) [26,45]. In this study, we evaluated whether PS could ameliorate inflammation and cartilage degradation in surgically induced osteoarthritis rats. Extended evaluation should be performed by measuring joint pain of experimental animals and by studying chondrocytes and synoviocytes to verify its effects on controlling pro-inflammatory cytokines, chemokines, and stress-related factors. 


\section{Conclusions}

The present investigation demonstrates that PS significantly improved surface cartilage damage, Mankin scores, mean femur and tibia AC thicknesses, and inflammatory cell numbers in rats with surgically induced OA. PS significantly decreased serum inflammatory cytokines and MMPs levels, which were elevated due to OA. Thus, it is posited that PS may be used as a novel potential therapeutic regime for various OA and may reduce the risk of cartilage loss and disease progression in the elderly with OA. Further detailed molecular mechanism studies are recommended to verify our findings.

Author Contributions: S.-H.L. and B.-R.C. conceived and designed the study. S.-H.L., E.-B.L., J.-H.C., H.-W.K. and S.-K.K. conducted experiments and analyzed the data. S.-H.L. and E.-B.L. wrote the manuscript. S.-H.L., H.-H.J., H.-W.K. and J.-S.L. reviewed the manuscript. All authors have read and agreed to the published version of the manuscript.

Funding: This research was supported by the grants PJ01586301 and PJ01327901 from the Rural Development Administration, Republic of Korea.

Institutional Review Board Statement: The study was approved by the Ethics Committee of the National Institute of Agricultural Sciences (protocol code NAS201804) and was conducted according to the guidelines for animal experiments in the protocol.

Informed Consent Statement: Not applicable.

Data Availability Statement: The study did not report any data.

Acknowledgments: The authors thank Mara Shyn Valdeabella for her review of the manuscript and Jung-Hyun Lim and Min-Sook Kim for their support of the animal experiment.

Conflicts of Interest: The authors declare no conflict of interest.

\section{References}

1. Dougados, M.; Nguyen, M.; Berdah, L.; Mazières, B.; Vignon, E.; Lequesne, M. Evaluation of the structure-modifying effects of diacerhein in hip osteoarthritis. Arthritis Rheum. 2001, 44, 2539-2547. [CrossRef]

2. Pavelká, K.; Gatterová, J.; Olejarová, M.; Machacek, S.; Giacovelli, G.; Rovati, L. Glucosamine sulfate use and delay of progression of knee osteoarthritis. Arch. Intern. Med. 2002, 162, 2113-2123. [CrossRef] [PubMed]

3. Tamura, T.; Ohmori, K. Rhein, an active metabolite of diacerein, suppresses the interleukin-1alpha-induced proteoglycan degradation in cultured rabbit articular chondrocytes. Jpn. J. Pharmacol. 2001, 85, 101-104. [CrossRef] [PubMed]

4. Goldring, M.B.; Goldring, S.R. Osteoarthritis. J. Cell Physiol. 2007, 213, 626-634. [CrossRef]

5. Hu, Y.; Chen, X.; Wang, S.; Jing, Y.; Su, J. Subchondral bone microenvironment in osteoarthritis and pain. Bone Res. 2021, 9, 20. [CrossRef]

6. Hu, W.; Chen, Y.; Dou, C.; Dong, S. Microenvironment in subchondral bone: Predominant regulator for the treatment of osteoarthritis. Ann. Rheum. Dis. 2020, 80, 413-422. [CrossRef] [PubMed]

7. Choi, B.R.; Kang, S.J.; Kim, J.L.; Lee, Y.J.; Ku, S.K. Anti-osteoarthritic effects of a mixture of dried pomegranate concentrate powder, eucommiae cortex, and achyranthis radix 5:4:1 (g/g) in a surgically induced osteoarthritic rabbit model. Nutrients 2020, 12, 852. [CrossRef]

8. Inomata, K.; Tsuji, K.; Onuma, H.; Hoshino, T.; Udo, M.; Akiyama, M.; Nakagawa, Y.; Katagiri, H.; Miyatake, K.; Sekiya, I.; et al. Time course analyses of structural changes in the infrapatellar fat pad and synovial membrane during inflammation-induced persistent pain development in rat knee joint. BMC Musculoskelet. Disord. 2019, 20, 8. [CrossRef]

9. Goldring, M.B.; Otero, M. Inflammation in osteoarthritis. Curr. Opin. Rheumatol. 2011, 23, 471-478. [CrossRef]

10. Rigoglou, S.; Papavassiliou, A.G. The NF-kB signalling pathway in osteoarthritis. Int. J. Biochem. Cell Biol. 2013, 45, 2580-2584. [CrossRef]

11. Conde, J.; Gomez, R.; Bianco, G.; Scotece, M.; Lear, P.; Dieguez, C.; Gualillo, O. Expanding the adipokine network in cartilage: Identification and regulation of novel factors in human and murine chondrocytes. Ann. Rheum. Dis. 2011, 70, 551-559. [CrossRef] [PubMed]

12. Rucci, N.; Capulli, M.; Piperni, S.G.; Cappariello, A.; Lau, P.; Frings-Meuthen, P.; Teti, A. Lipocalin 2: A new mechanoresponding gene regulating bone homeostasis. J. Bone Miner. Res. 2015, 30, 357-368. [CrossRef] [PubMed]

13. Lim, W.H.; Wong, G.; Lim, E.M.; Byrnes, E.; Zhu, K.; Devine, A.; Lewis, J.R. Circulating lipocalin 2 levels predict fracture-related hospitalizations in elderly women: A prospective cohort study. J. Bone Miner. Res. 2015, 30, 2078-2085. [CrossRef] [PubMed]

14. Gupta, K.; Shukla, M.; Cowland, J.B.; Malemud, C.J.; Haqqi, T.M. Neutrophil gelatinase-associated lipocalin is expressed in osteoarthritis and forms a complex with matrix metalloproteinase 9. Arthritis Rheum. 2007, 56, 3326-3335. [CrossRef] [PubMed] 
15. Katano, M.; Okamoto, K.; Arito, M.; Kawakami, Y.; Kurokawa, M.S.; Suematsu, N.; Kato, T. Implication of granulocytemacrophage colony-stimulating factor induced neutrophil gelatinase-associated lipocalin in pathogenesis of rheumatoid arthritis revealed by proteome analysis. Arthritis Res. Ther. 2009, 11, 1-12. [CrossRef] [PubMed]

16. Choi, W.S.; Chun, J.S. Upregulation of lipocalin-2 (LCN2) in osteoarthritic cartilage is not necessary for cartilage destruction in mice. Osteoarthr. Cartil. 2017, 25, 401-405. [CrossRef]

17. Qin, J.; Liu, Y.S.; Liu, J.; Li, J.; Tan, Y.; Li, X.J.; Magdalou, J.; Mei, Q.B.; Wang, H.; Chen, L.B. Effect of Angelica sinensis polysaccharides on osteoarthritis in vivo and in vitro: A possible mechanism to promote proteoglycans synthesis. Evid. Based Complement. Altern. Med. 2013, 2013, 794761. [CrossRef]

18. Messina, O.D.; Vidal Wilman, M.; Vidal Neira, L.F. Nutrition, osteoarthritis and cartilage metabolism. Aging Clin. Exp. Res. 2019, 31, 807-813. [CrossRef]

19. Bruyère, O.; Cooper, C.; Al-Daghri, N.M. Inappropriate claims from non-equivalent medications in osteoarthritis: A position paper endorsed by the European Society for Clinical and Economic Aspects of Osteoporosis, Osteoarthritis and Musculoskeletal Diseases (ESCEO). Aging Clin. Exp. Res. 2018, 30, 111-117. [CrossRef]

20. Cutolo, M.; Berenbaum, F.; Hochberg, M. Commentary on recent therapeutic guidelines for osteoarthritis. Semin. Arthritis Rheum. 2015, 44, 611-617. [CrossRef]

21. Akhtar, N.; Haqqi, T.M. Current nutraceuticals in the management of osteoarthritis: A review. Ther. Adv. Musculoskelet. Dis. 2012, 4, 181-207. [CrossRef] [PubMed]

22. Bortoluzzi, A.; Furini, F.; Scirè, C.A. Osteoarthritis and its management-Epidemiology, nutritional aspects and environmental factors. Autoimmun. Rev. 2018, 17, 1097-1104. [CrossRef] [PubMed]

23. Ravalli, S.; Szychlinska, M.A.; Leonardi, R.M. Recently highlighted nutraceuticals for preventive management of osteoarthritis. World J. Ortop. 2018, 9, 255. [CrossRef] [PubMed]

24. Li, Y.; Xiao, W.; Luo, W. Alterations of amino acid metabolism in osteoarthritis: Its implications for nutrition and health. Amino Acids 2016, 48, 907-914. [CrossRef]

25. Chen, Y.P.; Chu, Y.L. Tsuang, Y.H.; Wu, Y.; Kuo, C.Y.; Kuo, Y.J. Anti-inflammatory effects of adenine enhance osteogenesis in the osteoblast-like MG-63 cells. Life 2020, 10, 116. [CrossRef] [PubMed]

26. Ryu, B.; Qian, Z.J.; Kim, S.K. Purification of a peptide from seahorse, that inhibits TPA-induced MMP, iNOS and COX-2 expression through MAPK and NF-kappaB activation, and induces human osteoblastic and chondrocytic differentiation. Chem. Biol. Interact. 2010, 184, 413-922. [CrossRef]

27. Mattiuzzo, E.; Faggian, A.; Venerando, R.; Benetti, A.; Belluzzi, E.; Abatangelo, G.; Ruggieri, P.; Brun, P. In vitro effects of low doses of $\beta$-Caryophyllene, ascorbic acid and d-Glucosamine on human chondrocyte viability and inflammation. Pharmaceuticals 2021, 14, 286. [CrossRef]

28. Chun, J.M.; Lee, A.Y.; Nam, J.Y.; Lim, K.S.; Choe, M.S.; Lee, M.Y.; Kim, C.; Kim, J.S. Effects of Dipsacus asperoides extract on monosodium iodoacetate-induced osteoarthritis in rats based on gene expression profiling. Pharmaceuticals 2021, $12,615157$. [CrossRef]

29. Lee, Y.M.; Son, E.J.; Kim, S.H.; Kim, O.S.; Kim, D.S. Anti-inflammatory and anti-osteoarthritis effect of Mollugo pentaphylla extract. Pharm. Biol. 2019, 57, 74-81. [CrossRef]

30. Choi, B.K.; Lee, S.H.; Kim, N.S.; Cho, S.Y.; Jang, H.H.; Kim, J.B.; Lee, Y.M.; Yoon, S.G.; Lee, S.H. Anti-oxidative and anti-allergic effects of Salvia plebeia R. ethanol extracts. Korean J. Pharmacogn. 2014, 45, 332-337.

31. Lim, J.A.; Yun, B.W.; Baek, S.H. Antioxidative activity and nitrite scavenging ability of methanol extract from Salvia plebeia R. Br. Korean J. Med. Crop Sci. 2007, 15, 183-188.

32. Jang, H.H.; Cho, S.Y.; Kim, M.J.; Kim, J.B.; Lee, S.H.; Lee, M.Y.; Lee, Y.M. Anti-inflammatory effects of Salvia plebeia R. Br extract in vitro and in ovalbumin-induced mouse model. Biol. Res. 2016, 49, 1-11. [CrossRef] [PubMed]

33. Choi, J.K.; Oh, H.M.; Park, J.H.; Choi, J.H.; Sa, K.H.; Kang, Y.M.; Park, P.H.; Shin, T.Y.; Rho, M.C.; Kim, S.H. Salvia plebeian extract inhibits the inflammatory response in human rheumatoid synovial fibroblasts and a murine model of arthritis. Phytomedicine 2015, 22, 415-422. [CrossRef]

34. Weng, X.C.; Wang, W. Antioxidant activity of compounds isolated from Salvia plebeian. Food Chem. 2000, 71, 489-493. [CrossRef]

35. Lee, S.H.; Kim, H.W.; Lee, M.K.; Kim, Y.J.; Asamenew, G.; Cha, Y.S.; Kim, J.B. Phenolic profiling and quantitative determination of common sage (Salvia plebeia R. Br.) by UPLC-DAD-QTOF/MS. Eur. Food Res. Technol. 2018, 244, 1637-1646. [CrossRef]

36. He, B.; Zhang, B.; Wu, F.; Wang, L.; Shi, X.; Qin, W.; Lin, Y.; Ma, S.; Liang, J. Homoplantaginin inhibits palmitic acid-induced endothelial cells inflammation by suppressing TLR4 and NLRP3 inflammasome. J. Cardiovasc. Pharmacol. 2016, 67, 93-101. [CrossRef]

37. Kang, S.J.; Kim, J.W.; Kim, K.Y.; Ku, S.K.; Lee, Y.J. Protective effects of calcium gluconate on osteoarthritis induced by anterior cruciate ligament transection and partial medial meniscectomy in Sprague-Dawley rats. J. Orthop. Surg. Res. 2014, 9, 14. [CrossRef]

38. Kim, J.W.; Cho, H.R.; Ku, S.K. Efficacy test of Polycan, a beta-glucan originated from Aureobasidium pullulans SM-2001, on anterior cruciate ligament transection and partial medial meniscectomy-induced-osteoarthritis rats. J. Microbiol. Biotechnol. 2012, 22, 274-282. [CrossRef]

39. Na, J.Y.; Song, K.B.; Kwon, Y.B.; Kim, D.G.; Lee, J.K.; Jo, H.K.; Kwon, J.K. Effects of HPL-04 on degenerative osteoarthritis. J. Korean Soc. Food Sci. Nutr. 2014, 43, 30-39. [CrossRef] 
40. Bove, S.E.; Laemont, K.D.; Brooker, R.M.; Osborn, M.N.; Sanchez, B.M.; Guzman, R.E.; Hook, K.E.; Juneau, P.L.; Kilgore, K.S. Surgically induced osteoarthritis in the rat results in the development of both osteoarthritis-like joint pain and secondary hyperalgesia. OsteoArthritis Cartil. 2006, 14, 1041-1048. [CrossRef]

41. Nam, D.E.; Kim, O.K.; Shim, T.J.; Kim, J.H.; Lee, J. Effect of Boswellia serrata extracts on degenerative osteoarthritis in vitro and in vivo models. J. Korean Soc. Food Sci. Nutr. 2014, 43, 631-640. [CrossRef]

42. Nagase, H.; Woessner, J.F., Jr. Matrix metalloproteinases. J. Biol. Chem. 1999, 274, 21491-21494. [CrossRef]

43. Bresnihan, B. Pathogenesis of joint damage in rheumatoid arthritis. J. Rheumatol. 1999, 26, 717-719.

44. Pelletier, J.P.; Raynauld, J.P.; Caron, J.; Mineau, F.; Abram, F.; Dorais, M.; Haraoui, B.; Choquette, D.; Martel-Pelletier, J. Decrease in serum level of matrix metalloproteinases is predictive of the disease-modifying effect of osteoarthritis drugs assessed by quantitative MRI in patients with knee osteoarthritis. Ann. Rheum. Dis. 2010, 69, 2095-2101. [CrossRef]

45. Blom, A.B.; van Lent, P.L.; Libregts, S.; Holthuysen, A.E.; van der Kraan, P.M.; van Rooijen, N.; van den Berg, W.B. Crucial role of macrophages in matrix metalloproteinase-mediated cartilage destruction during experimental osteoarthritis: Involvement of matrix metalloproteinase 3. Arthritis Rheum. 2007, 56, 147-157. [CrossRef] [PubMed]

46. Gómez, R.; Conde, J.; Scotece, M.; Gómez-Reino, J.J.; Lago, F.; Gualillo, O. What's new in our understanding of the role of adipokines in rheumatic diseases? Nat. Rev. Rheumatol. 2011, 7, 528-536. [CrossRef] [PubMed]

47. Wilson, R.; Belluoccio, D.; Little, C.B.; Fosang, A.J.; Bateman, J.F. Proteomic characterization of mouse cartilage degradation in vitro. Arthritis Rheum. 2008, 58, 3120-3131. [CrossRef] [PubMed]

48. Zamora, R.; Vodovotz, Y.; Billiar, T.R. Inducible nitric oxide synthase and inflammatory diseases. Mol. Med. 2000, 6, 347-373. [CrossRef]

49. Hwang, J.H.; Kim, K.J.; Ryu, S.J.; Lee, B.Y. Caffeine prevents LPS-induced inflammatory responses in RAW264.7 cells and zebrafish. Chem. Biol. Interact. 2016, 248, 1-7. [CrossRef] 